\title{
从罗马“古迹区”百年保护历程看遗址保护与城市发展 的冲突及共生
}

\author{
Coexistence and Conflict Between Archaeological Site Preservation and City Development: The Study of \\ Rome Monumental Zone's 100-Year History of Preservation
}

杜寒

Du Qian

\begin{abstract}
摘要: 考古遗址在面对城市发展所带来的建筑用地扩 张时极其脆弱。近年来我国遗址保护与城市化存在诸 多矛盾, 而城市化水平已比较稳定的西方国家早年也 有类似情形。意大利罗马 “古迹区”保护始于 19 世纪 早期, 保护区划形成于 19 世纪末期, 后由于两次世界 大战与城市化的影响逐渐碎片化, 自 20 世纪后半叶开 始进行内部肌理的织补。该案例充分体现了遗址保护 与城市发展之间的辩证关系, 其中存在的问题以及解 决方法对我国当前遗址保护规划颇具参考价值。

Abstract: The archaeological site is extremely fragile in the face of fast urbanization. How to protect the archaeological site during the urbanization is not only an issue for China nowadays, but also a problem for Western countries before. The preservation of the "Archaeological Zone" in Rome began since the early 19th century. The conservation zone was officially settled in the late 19th century but fell into fragmentation due to the impact of the two world wars and urbanization. This process was alleviated since the second half of the 20th century. The study case fully embodies the conflict between archaeological site protection and city development, which can provide China's current site protection planning with great value.
\end{abstract}

关键词: 考古遗址; 城市化; 保护区划;

遗址保护与利用; 罗马

Keywords: Archaeological Site; Urbanization;

Planning of Conservation;

Conservation and Use of Archaeological Site; Rome

作者: 杜骞, 博士, 上海交通大学建筑学系助理研究员。 qian.du@sjtu.edu.cn

\section{引言}

大型考古遗址保护既是近年来我国文化遗产保护的难点, 也是城市规划 领域的新课题。根据《中国城市统计年鉴》数据, 2005-2015 年, 我国城市 建设用地从 $26141 \mathrm{~km}^{2}$ 增长到 $38488 \mathrm{~km}^{2}$ [1]。随着城市建设范围的扩张, 一些 位于城市中心地区的遗址被房地产开发所䖯食, 一些位于城乡结合部或城市郊 区的遗址成为城市中心区用地的组成部分 ${ }^{[2]}$ 。大型考古遗址之所以难以保护, 首先在于考古遗址所涉及的土地或分布有古文化的遗存, 或埋有尚未挖掘的文 物, 一旦进人文物保护体系, 则不具备直接的生产功能或居住功能, 这与快速 城市化进程中建设用地的扩张形成了明显矛盾; 其次, 考古遗址保护的周期长、 投人大而收效慢，所历经的考古挖掘、保护处理、展示利用通常由不同机构参 与并分阶段完成, 进一步加大了遗址整体保护的难度。

事实上, 考古遗址保护与城市化的矛盾并非我国特有的问题, 虽然世界 各国政体、文化形态存有差异, 但从城市规划角度, 考古遗址的保护与利用 从本质而言多为土地资源公有化并逐渐对公众开放的过程。西方国家当前的 成功保护案例固然具有参考价值, 但也不应忽略它们早年在城市化阶段, 与 中国当前社会经济条件类似时期的遗址保护实践, 看它们当时的保护意识如 何, 采取了哪些保护手段, 是否存在失误以及如何解决。对于这一历史过程 的分析, 将有利于我们预估考古遗址保护可能出现的问题并有所准备。

本文的研究对象一一意大利罗马 “古迹区”, 遗产价值重大, 保护实践 开展较早。长达一个世纪的保护历程留下了丰富的研究资料, 是探讨遗址与 城市相互关系的典型案例。

\section{1 “古迹区”的概念及遗存构成}

罗马 “古迹区” 就字面而言是一个广义的概念, 这是由于它提出 的年代较早, 并没有在词义上直接体现出保护对象。具体而言, “古迹 区”指的是当前罗马市中心的古罗马时代遗址群（图 1), 包括斗兽场

(Colosseo)、古罗马广场（Foro Romano）、帝国广场（Fori Imperiali）、卡 比托利欧山 (Campidoglio)、帕拉蒂尼山(Palatino)、马克西姆竞技场 (Circo Massimo）所构成的核心区域, 以及附近的卡拉卡拉浴场（Terme di 
Caracalla)、提图斯浴场（Terme di Tito）、图拉真浴场（Terme di Traiano) 和尼禄金宫 (Domus Aurea)。

这一带原是古罗马帝国的政治、文化中心, 后由于帝国 衰败、蛮族人侵、城市人口减少而逐渐被边缘化，加之排水 系统㿈疾，位于低洼地带的建筑群慢慢被掩埋。在文艺复兴 时期, 由于教皇大兴土木, 对建筑石材肆意采挖, 宫殿建筑 进一步沦为废墟。之后伴随着城市的复兴, 古罗马遗址区西 北部被逐渐发展的居民区所叠压。

参照 1748 年意大利建筑师诺里 (Giambattista Nolli) 所绘制的罗马城市地图（图 2)，18 世纪时的古罗马遗址区 仍处于城乡交界处。同时期雕版画家皮拉内西（Giovanni Battista Piranesi）的一系列雕版印刷作品更直观地表现了遗 址区的调敉, 其中 1756 年的一幅版画（图 3) 描绘了半掩 埋于地下的塞维鲁凯旋门（Arco di Settimio Severo）往东南 方至提图斯凯旋门 (Arco di Tito) 的景象, 远处斗兽场的轮 廓隐约可见。

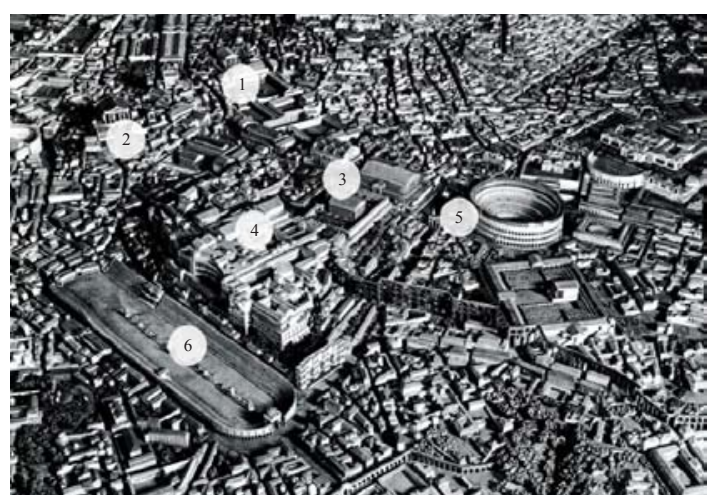

注：1. 古罗马广场；2. 卡比托利欧山；3. 帝国广场； 4. 帕拉蒂尼山；5.斗 兽场; 6. 马克西姆竞技场。

图 1 罗马在帝国时代的城市复原推测 (吉斯蒙蒂 [Italo Gismondi] 于 1933-1935 制作, 现收录于古罗马文明博物馆 )

资料来源 : 参考文献 [3]

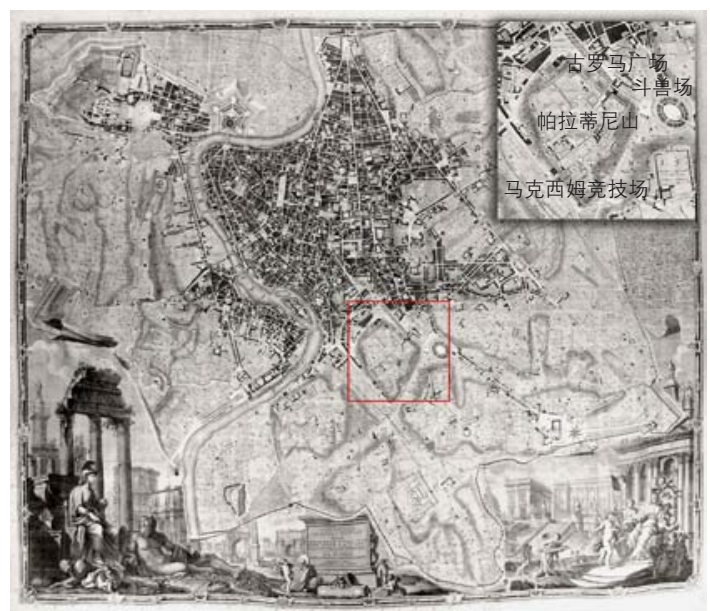

图 2 诺里所绘罗马地图 (1784)

资料来源 : http://isites.harvard.edu/icb/icb.do?keyword=k84161\&pageid=icb.page468711

\section{9 世纪早期的罗马遗址保护—“古迹区” 的} 雏形

罗马遗址真正走人公共视野始于新古典主义运动, 与 考古学的兴起有着千丝万缕的联系。拿破仑统治罗马期 间（1789-1814 年), 法国人率先开展了一系列挖掘活 动, 并成立了 “古迹与城市建造委员会” (Commission des Monumens et Batimens Civils) 来管理罗马的文化资产。1813 年, 法国提出了第一份有关遗址区的规划一《卡比托利欧 公园规划》(Plan du Jardin du Capitole)（图 4)。该规划包括 斗兽场、帕拉蒂尼山和古罗马广场三个主要部分, 采用林荫 大道作为公园的边界以屏蔽周围的市井环境, 拓宽斗兽场的 周边道路, 在帕拉蒂尼山顶上建造几何形式的、规整的园林。

显然, 这是以利用为主要目的的规划, 只对暴露于地表 的遗迹进行展示, 不涉及大规模考古挖掘, 因此大部分遗迹 埋藏区以留白的形式出现。这一规划由于拿破仑政权的失败 而流产, 但多少影响了之后的遗址区规划。此后罗马经历了 教皇国政权动荡与意大利民族统一战争, 遗址的整体规划少

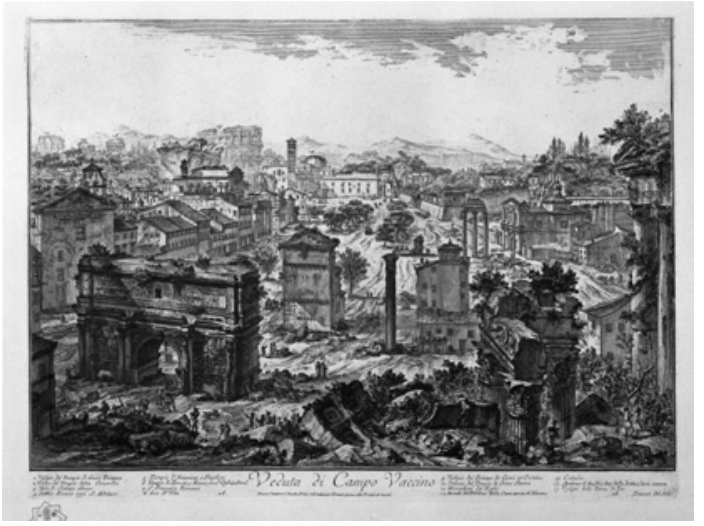

图 3 皮拉内西所绘版画 (1756)

资料来源 : http://www.wikiart.org/en/giovanni-battista-piranesi/view-of-campo-vaccino

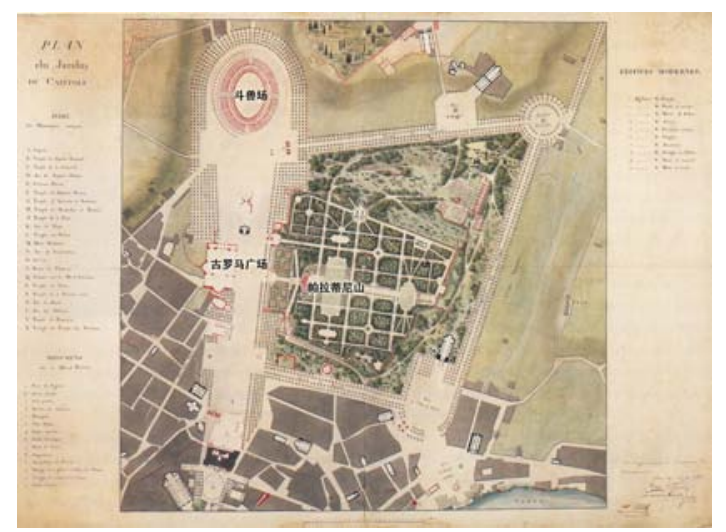

图 4 法国建筑师贝赫托 ( Louis-Martin Berthault ) 提出的《卡比托 利欧公园规划》(1812)

资料来源 : Ordine degli Architetti Pianificatori Paesaggisti e Conservatori di Roma e Provincia Dipartimento dei Beni Culturali, Convegno internazionale Roma, Casa dell'architettura 27 maggio 2014 
有提及, 但不乏对单个考古遗址点的加固与修复工程。遗址 区的总体规划再次被提出时已经是 1887 年, 正值意大利王 国迁都罗马 16 年后。

\section{3 意大利王国成立至 20 世纪早期——“古迹区” 保护区划的确立}

19 世纪的欧洲在工业革命的影响下, 人口增长, 城市 扩张, 交通、给排水管线被重新规划。这一系列更新换代的 建设活动在欧洲各大城市轰轰烈烈地展开, 但罗马由于教皇 统治时期对资产阶级发展的限制, 城市建设明显滞后于欧洲 其他大都会 ${ }^{[4]}$ 。意大利首都迁至罗马时, 亟须改造老城、扩 建新城以满足一个现代化首都运作的要求。当时罗马的人口 是 22 万 $^{[4] 3}$ 。

从 1873 年罗马的第一张城市规划图（图 5) 可看出, 从斗兽场往南仍是城市发展的边缘地带, 但斗兽场的东部和 北部已经划定了建设用地。罗马打算短期内完成 8 万人口 的增长量 ${ }^{[5]}$, 因此计划向老城区的东面和北面开辟大片居住 区, 在朝海的西部设立工业新区; 保持老城区的格局, 仅拆 掉一部分沿街建筑用于拓宽道路; 此外, 规划决定扩建距斗 兽场不过 $1.5 \mathrm{~km}$ 的特米尼 (Termini) 车站作为城市的中心 火车站, 并新建一条连接斗兽场与火车站的道路一加富尔 路 (Via Cavour) 作为交通干道。这意味着古罗马遗址将成 为从火车站出发去往城市西南部的必经之地。1 873 年的规 划还未实施就被 1883 年的规划所取代 (图 6), 新规划在总 体思路上延续了前一个规划, 但对土地使用属性给子了说明, 古罗马遗址一带被规划为城市的公共绿地。

此时的遗址区一方面承受着城市扩张的压力, 一方面作 为新意大利首都必不可少的文化象征, 地位举足轻重。为了

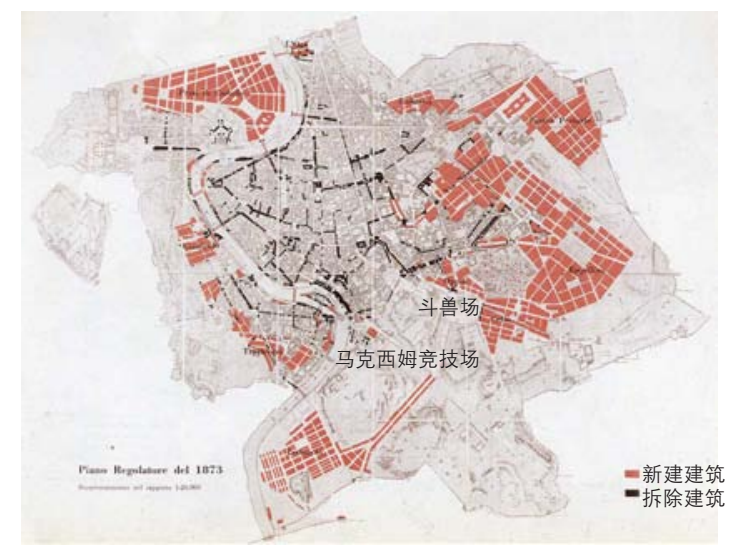

图 51873 年罗马城市规划

资料来源 : http://aut.uniroma3.it/?cat=5
调解两者之间的矛盾, 时任罗马政府顾问的巴切利 (Guido Baccelli）在 1887 年成立了皇家委员会着手进行规划, 罗马“古 迹区” 1 的概念由此诞生。委员会划定保护范围, 横向从奥 皮乌斯山 (Oppio) 到马克西姆竞技场, 纵向从卡比托利欧 山延伸到罗马奥勒良城墙的塞巴斯蒂城门 (Porta Sebastiano), 将考古遗址与城市绿地统筹规划, 总面积达到 $95.4 \mathrm{hm}^{2[5]}$ 。如 此之大的保护范围在于维系考古景观的连续性以及历史环境 的完整性, 超越单个遗址点的保护。规划特意将古迹区的东 南端连接至阿庇亚古道 ${ }^{2}$ (Via Appia Antica), 以此形成自市 中心往东南郊方向逐渐敞开的考古景观长廊。规划摒弃了法 国园林的几何造型，尽量保留原有的空间肌理（图 7)。

这一规划很快得以通过, 紧接而来的是土地征用, 征用 补偿依据当时三年内土地价格的平均值确定。在意大利繁琐 的官僚程序与资金划拨问题面前, 土地收购历时 20 年, 由

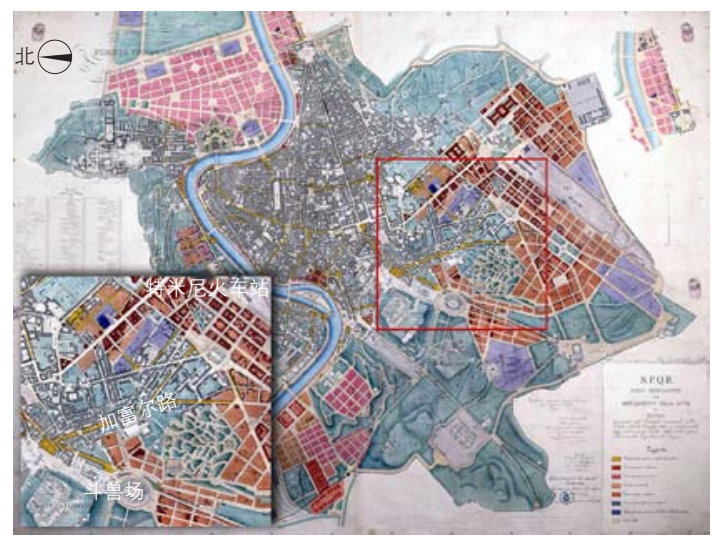

图 61883 年罗马城市规划

资料来源 : http://aut.uniroma3.it/?cat $=5$

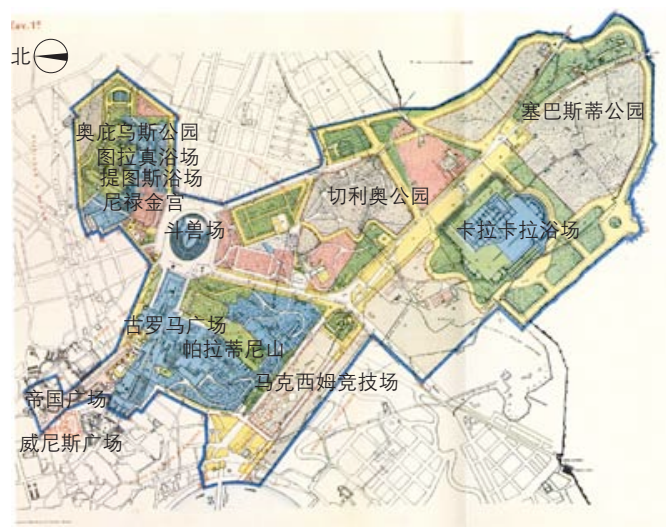

注: 蓝线为边界, 蓝色区块为国有资产, 红色为罗马市资产, 黄色和 绿色为预备征用为道路和园林的地块, 灰色部分无需征收。

图 71887 年罗马古迹区规划

资料来源 : 参考文献 [3]27

(1) Zona Monumentale 也可翻译为 “纪念物区”, 但考虑到威尼斯宪章对 monument 的译法为古迹, 本文采用“古迹区”。

(2) 阿庇亚古道为“条条大道通罗马” 中的一条。 
国家和罗马市政府共同出资 790 万里拉, 其中 290 万来源于 罗马市 ${ }^{[5]}$ 。虽然最后征收的范围与之前规划相比略有出人, 但是公共资产已经占了绝对优势。征用同时逐步扩大考古遗 址的揭露面积, 在 20 世纪初期, 古迹区内的主要考古与清 理工作基本结束（图 8)。

“古迹区”这一概念至少在当时是超前的, 较国际保护 宪章对于遗址环境的整体性保护理念早了 77 年 ${ }^{1}$ 。如果罗 马 “古迹区” 没有提出并付诸实际, 那后期的留存至多是图 7 中分散的蓝色区块。然而, 古迹区的规划有两点值得注意: 首先, 这是一个以公园为出发点的规划, 没有在边界设置围 墙, 完全是开敞式的, 市民可自由进出; 其次, 为了在视觉 上与大体量的建筑遗存协调, 古迹区内部的主要道路与边界 采用了宽敞笔直的林荫道, 作为考古景观大道。这些在当时 看来并无不妥之处, 却为古迹区后期的碎片化埋下了隐患。

\section{4 法西斯政权时代至 1960 年代——“古迹区” 的 危机与碎片化}

1922 年, 意大利法西斯政权时代开始, 墨索里尼对当时 罗马的建设确立了两个目标——满足城市发展需要与实现民 族伟大复兴 ${ }^{[4] 36}$ 。前者旨在改善罗马的居住环境, 从扩建居民 区和治理交通人手; 后者主要通过法西斯主义建筑实现。“建 筑是一种权力的雄辩术。” (2)古罗马建筑所展现的高大、权 威成为政治意志的最好代言。墨索里尼所推崇的法西斯主义 美学也伸向了罗马古迹区, 在他看来, 庄重雄伟的遗址古迹 不可与琐碎的民居并列, 必须扫清遗址周边的市井风貌 ${ }^{[4] 39}$, 由此展开了一系列的拆、建工程。

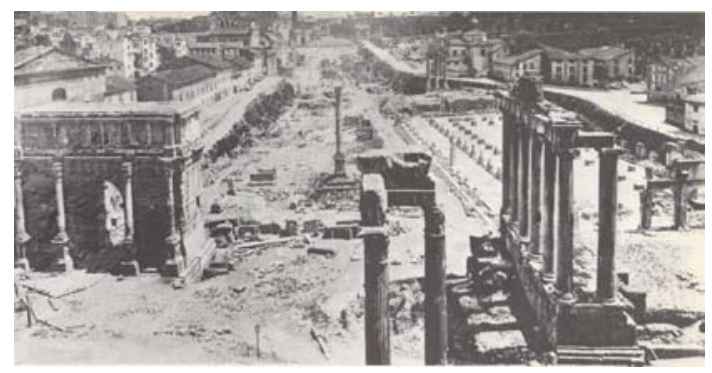

图 820 世纪初古罗马广场图像 资料来源: 参考文献 [8]
1931 年, 墨索里尼致力于修建一条连通古、今罗马的 帝国大道 (Via dei Fori Imperiali), 以威尼斯广场的维托里亚 诺纪念堂 $^{(3)}$ 为起点, 直接指向斗兽场 (图 9)。道路的修建在 一年内摧毁了 3 万 $\mathrm{m}^{2}$ 的历史街区 ${ }^{(4)}$ 。仓促的工期既无法保 证考古, 也毁坏了地下的历史遗迹。帝国大道于 1932 年竣工, $35 \mathrm{~m}$ 宽, $850 \mathrm{~m}$ 长。落成不久墨索里尼就在帝国大道上进行 了阅兵, 这条大道也成为日后举办重大庆典及公共活动的场 所 (图 10)。

帝国大道只是墨索里尼规划蓝图的一步, 他从 1935 年 开始在 1931 年规划基础上着手罗马西南部的新区 (EUR), 以实践法西斯主义建筑 (图 11)。新区需要一条高速公路连

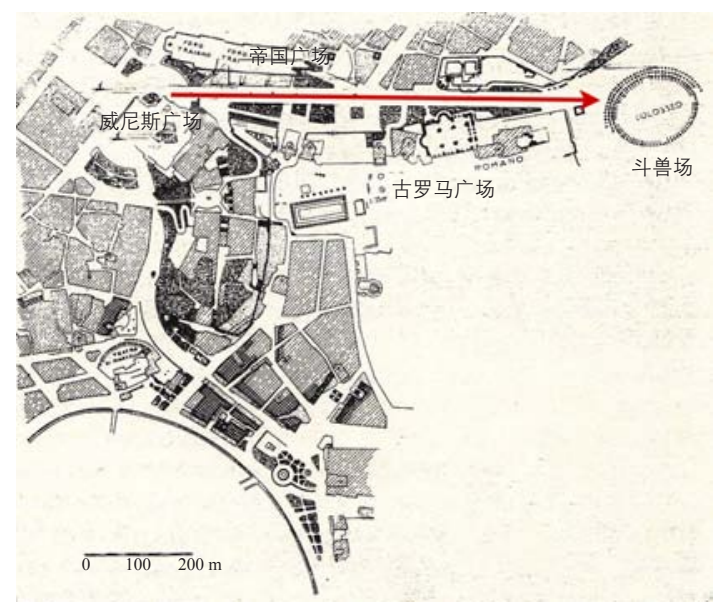

图 9 帝国大道修建后 资料来源 : 参考文献 [9]

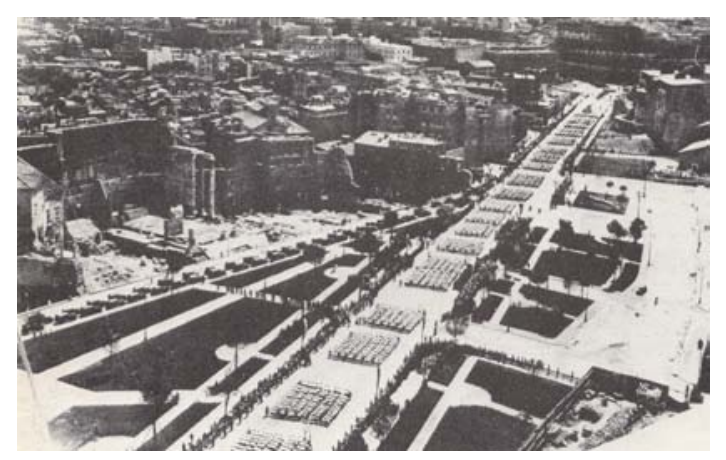

图 10 帝国大道 1932 年落成后的阅兵典礼 资料来源: 参考文献 [8]94

(1)《威尼斯宪章》(The Venice Charter for the Conservation and Restoration of Monuments and Sites) 第一条：历史古迹的要领不仅包括单个建筑物， 而且包括能从中找出一种独特的文明、一种有意义的发展或一个历史事件见证的城市或乡村环境。这不仅适用于伟大的艺术作品, 而且适用 于随时光逝去而获得文化意义的过去一些较为朴实的艺术品; 第六条古迹的保护包含着对一定规模环境的保护。凡传统环境存在的地方必须 予以保存, 决不允许任何导致改变主体和颜色关系的新建、拆除或改动。

(2) 引自尼采原文 “In architecture the pride of man, his triumph over gravitation, his will to power, assume a visible form. Architecture is a sort of oratory of power by means of forms"。

(3) 维托里亚诺纪念堂 (Monumento nazionale a Vittorio Emanuele II), 1885-1927 年间建造。

(4) 以执政者的眼光来看当时的拆除街区不过是罗马的贫民窟, 并没有保留价值。 
接至罗马老城, 哥伦布大道 (Via Cristoforo Colombo) 由此 诞生, 它的起点正好位于古迹区末端的奥勒良城墙脚下。如 此一来, 从哥伦布大道北上穿过古迹区内宽敞笔直的林荫道 进人帝国大道, 成为新区与市中心之间最佳的交通路线。

1945 年法西斯政权结束, 但所形成的交通网络长久地 烙印在了古迹区内。二战后的罗马百废待兴, 但也正是意 大利经济发展的黄金时期, 大批来自中、南部的移民涌向 罗马。1870 年罗马人口 22 万, 1900 年 50 万, 1930 年 100 万, 1960 年 200 万 $^{[5]}$ 。罗马继续向四周扩建, 地产投机商 开发的住宅小区在罗马市郊蔓延, 城市化愈演愈烈。原本 属于城乡交界地带的古迹区, 已经完全被围剿在城市建设 中（图 12）。

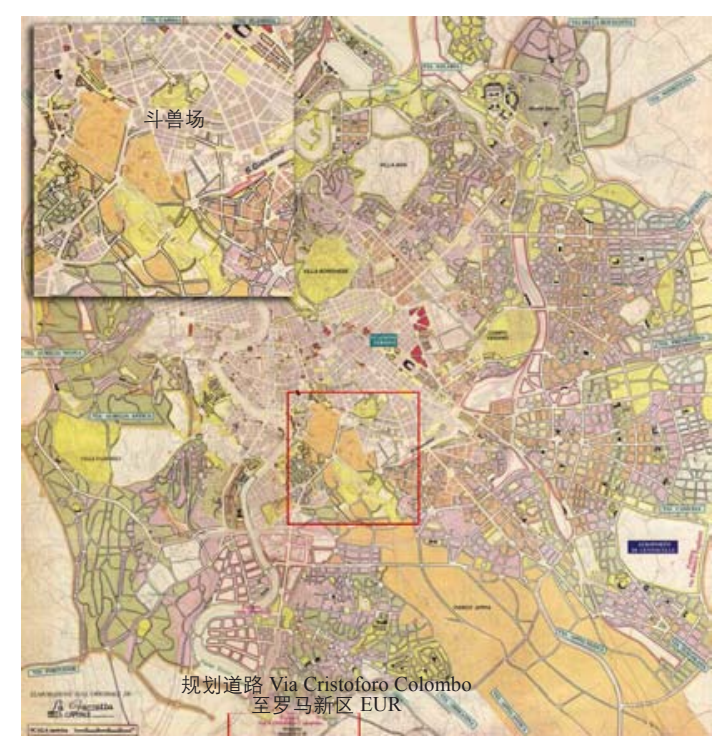

图 11 1931 年罗马城市规划

资料来源 : http://www.cittasostenibili.it/urbana/Scheda-13/urbana_Scheda_13.htm

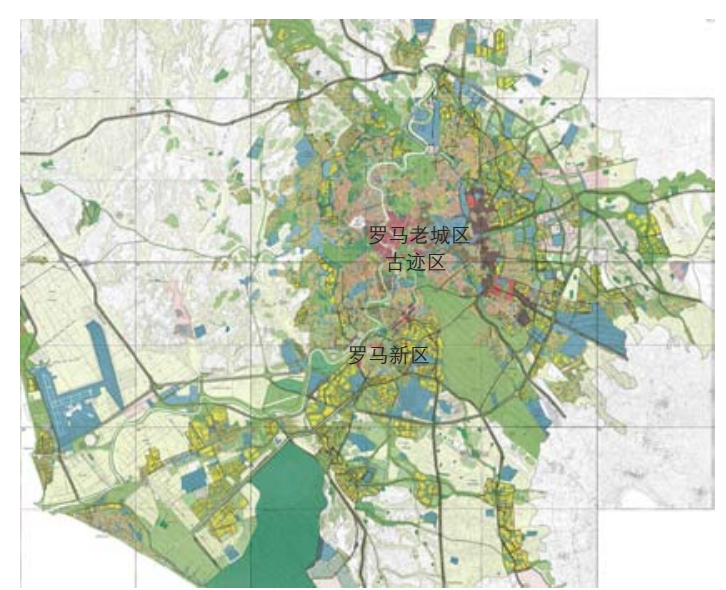

图 121962 年罗马城市规划

资料来源 : http://www.cittasostenibili.it/urbana/Scheda-13/urbana_Scheda_13.htm
由于早年规划的效力, 古迹区幸免于城市化的蚕食, 却 被交通流线所解体。终年穿梭于古迹区的车流不断, 尤其是 帝国大道, 交通高峰期的车流量为 2000 2 200 辆/小时, 占罗马车流量的 $57 \%$ (1980 年 12 月数据) ${ }^{[4 \mid 299}$ 。而椭圆形 的斗兽场成了绝佳的交通环岛, 疏导来自五个方向的车流 (图 13)。且不说古迹区庄重、宁静氛围荡然无存, 仅汽车 尾气对遗址造成的腐蚀、污染就已经令人扼腕叹息。

\section{0 年代至今——“古迹区” 的修补}

1970 年代末期, 进人了罗马古迹区保护以及城市化反 思阶段, 事实上这一时期也是罗马市人口增长的拐点。此 时的遗址保护变得更为主动, 成立于 1974-1975 年的意 大利 “文化遗产与环境部” (Ministero per i Beni Culturali e Ambientali） (1) 代替之前政府的跨部门管理委员会成为文化 遗产保护的专职机构。1980 年该部与罗马市长协商, 撤销 了穿过古迹区西端的一条次级交通道路—（Via del Foro Romano), 恢复古罗马时代的地坪, 原本两个割裂的考古遗 址区块就此打通（图 14）。

帝国大道依旧是众矢之的, 对于撤销与否争论不断。支 持者从古罗马遗址非同寻常的价值出发, 认为关闭大道能显 著减少古迹区的交通负荷, 并可以开启新一轮的考古挖掘, 回归最初考古公园的设想（图 15）; 而反对者则认为罗马古 迹区没有必要成为第二个庞贝, 需要以开敞的姿态与当代城 市融合。

在此起彼伏的争论声中, 政府做了一个折衷的尝试一 从 1981 年 2 月 1 日起对帝国大道进行周日限行, 将这一活动 命名为 “行人的周日”。看似是一小步, 但为了得到市民的 理解, 开放了刚修复完毕的凯撒广场和图拉真广场, 在古迹 区内组织遗址历史讲解、音乐会等, 旨在拉近遗址与普通市 民的距离。市民对此作出了积极响应, 而这与其归结于民众 觉醒的文化热情, 不如说是社会发展到一定阶段, 城市化进

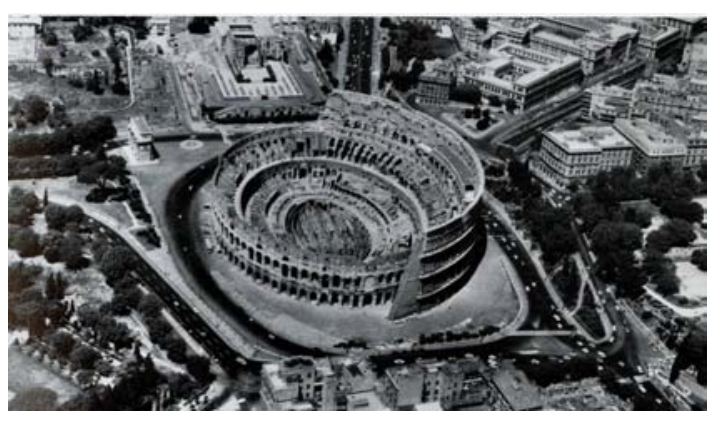

图 1320 世纪中期的斗兽场周边交通 资料来源 : 参考文献 $[3] 81$

(1) Ministero per i Beni Culturali e Ambientali，现名意大利文化遗产与活动部 Ministero dei Beni e delle Attività Culturali。 

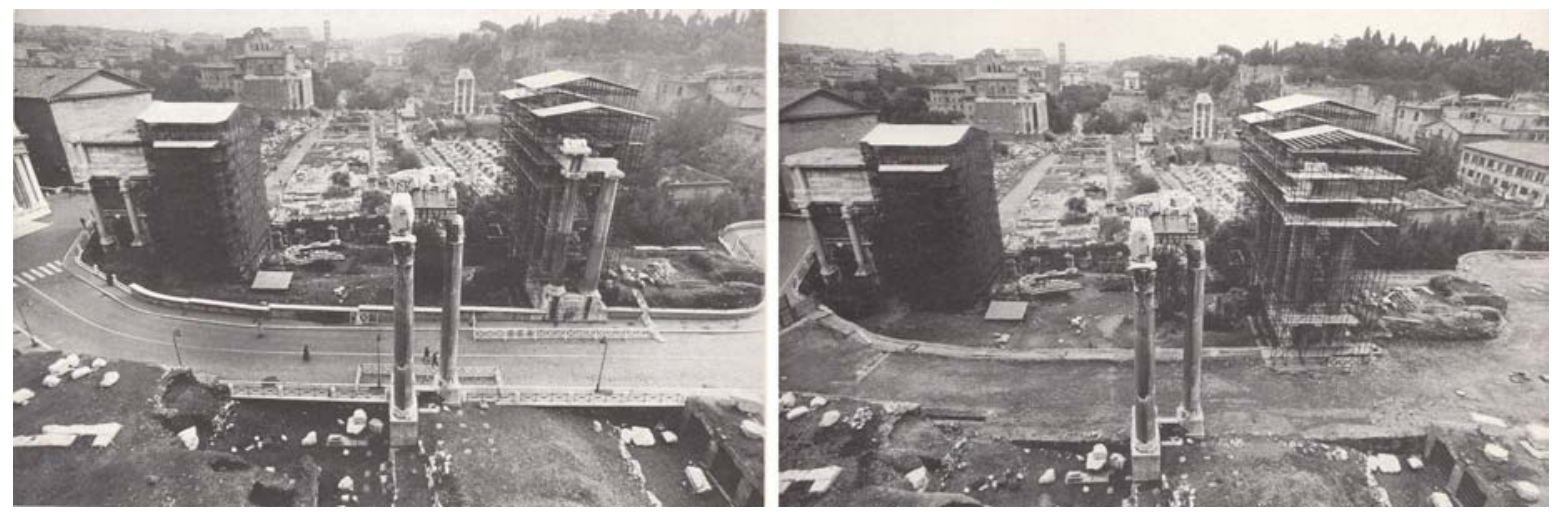

图 14 古罗马广场路撤销前后对比 资料来源 : 参考文献 [4]292-293

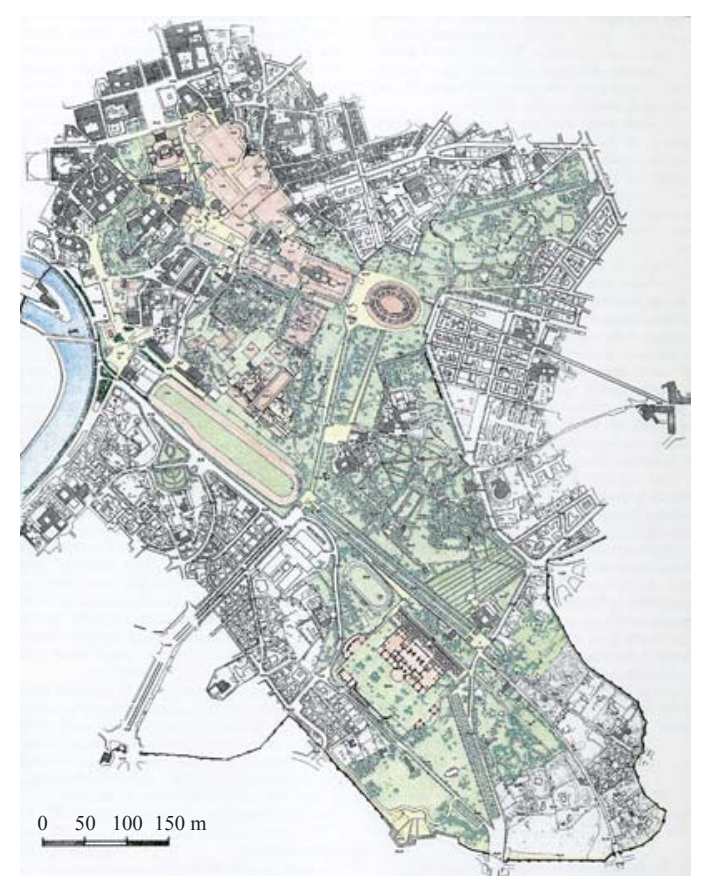

图 151980 年代初期古迹区的整体规划（虽被再次提出，但因涉及的 调整过大, 近期不具备操作性 )

资料来源 : 参考文献 [3]61

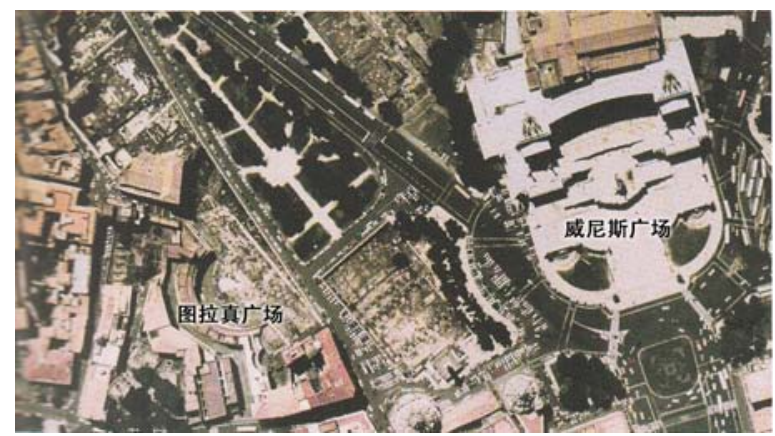

图 16 帝国广场挖掘前后对比

资料来源 : 参考文献 [10]
程放缓之后, 大众对于提高生活品质的诉求。考古遗址、公园、 绿地, 这些社会发展所牺牲和忽略的东西开始变得宝贵。

尽管撤销帝国大道为时尚早, 却不妨碍道路两侧的考古 活动。从某种意义而言, 法西斯时代大刀阔斧修建的帝国大 道间接扫清了考古挖掘所需面对的居民区叠压问题。1998 年 启动的考古活动进一步扩大了遗址的揭露面积, 从图 16 可 以看出帝国大道两旁原有的绿化已经被移除, 取而代之的是 最新考古挖掘后的遗址露天展示。自 2013 年, 罗马市对帝 国大道进行私家车限行, 只允许公交车和行人通行, 并积极 向公众征询帝国大道的整治方案。

意大利政府能够如此坚持古迹区的修补, 既得力于学 界与社会與论的支持, 也离不开罗马本身交通状况的改善 和政策引导。自 1955 年罗马第一条地铁建成以来, 现今罗 马市的轨道交通包括 4 条地铁、3 条城市铁路以及包括机场 快线在内的 9 条城际铁路, 人们对汽车的依赖程度已大大 降低。此外不得不提的是, 罗马自 2004 年开始实行交通限 制区 (ZTL: Zona a Traffico Limitato), 除公交车和出租车外, 所有公私车辆必须持有市政府发放的 “历史中心区车辆通行 证” 才能在限定的时段 ${ }^{1}$ 进人市中心。这样, 罗马市中心行

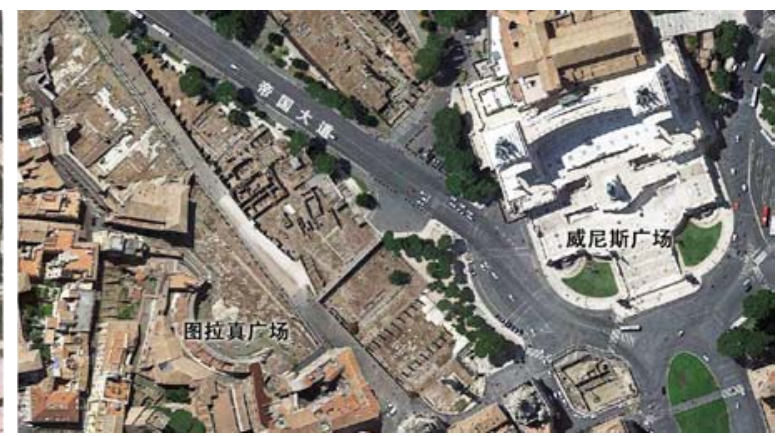

(1) 罗马目前的交通限制时段为周一至周五, 6:30-18:00, 周六 14:00-18:00, 周日不设限。 
驶的汽车数量至少被压缩掉一半 ${ }^{[6]}$ 。近年来, 古迹区修补更 是与罗马整体环境的改善相统筹, 罗马自市中心向外被划分 为三个车辆限行带, 分别对应污染物排放指标, 有效遏制了 尾气对古迹所造成的侵蚀。

如今, 当我们将 1887 年古迹区的范围标识在当今的卫 星地图, 并和城市规划图相比较, 可以发现古迹区的整体性 基本得到保留, 但其内部的形式、分区、管理都与早期的规 划有所差异 (图 17)。古迹区的西北端是考古遗址的集中展 示区, 斗兽场、帕拉蒂尼山、古罗马广场实行付费参观, 设 置景点联票, 游客人数在 2014 年达到 617 万人 ${ }^{[7]}$, 遥遥领 先于其他意大利旅游景点 ${ }^{1}$; 帝国广场目前只接受团队的预 约参观; 马克西姆竞技场成为免费参观区和大型活动场地。 距离稍远的卡拉卡拉浴场、尼禄金宫等遗址点由于交通和考 古挖掘等因素, 在游览管理上相对独立, 环绕它们的奥皮乌 斯公园、切利奥公园和塞巴斯蒂公园则作为市民公园, 免费 开放。以上区域连同罗马市中心的其他考古资产, 目前由意 大利文化遗产与活动旅游部下设的 “罗马考古、艺术与景观 特别管理局” (Soprintendenza Speciale Archeologia, Belle Arti e Paesaggio di Roma）进行管理与利用。

\section{6 小结与启示}

纵观罗马 “古迹区”一个多世纪的坎坷与起伏, 可以发
现国家对它的保护赶在了城市化吞并这一区域之前, 但之后 逐渐被建设活动所围剿, 嵌套在了城市的交通格局中, 在一 系列连锁反应下趋于碎片化。古迹区若想走向封闭式管理运 营的考古公园, 则需对内部的几条交通干道进行改造, 触及 整个城市交通系统甚至产业布局的调整, 牵一发而动全身。 但无论如何, 罗马在一个世纪前的 “古迹区” 概念的确立以 及为此付诸的努力已经很大程度地争取到了后期的主动权。 毕竟, 没有人能预料到罗马一个世纪后的人口会增长 10 倍, 城市面积是原来的 15 倍 ${ }^{[3]} 57$ 。

考古遗址保护如同城市化洪流中的逆水行舟, 罗马古迹 区的经验也给了我们不少启示。

（1）从时间角度看, 考古遗址的保护漫长而艰巨。罗马 古迹区的维形与初步保护可以追溯到 19 世纪早期, 保护区 划形成已是 19 世纪末, 大规模的考古挖掘集中在 20 世纪前 叶, 但真正对公众开放展示利用则到了 20 世纪后半叶。在 这一历程中, 考古遗址保护难度与城市化速度正相关 : 人口 大规模增长阶段的遗址保护步履维艰, 必须依靠强有力的规 划; 而社会结构趋于稳定时, 遗址的保护较好推进, 社会效 益逐渐展现, 适宜进行考古遗址区与周边环境的提升。因此, 有必要把握遗址保护与城市化的规律及关键时间点, 因势利 导, 循序渐进。

（2）从空间角度看, 处于城乡交界处的考古遗址保护需

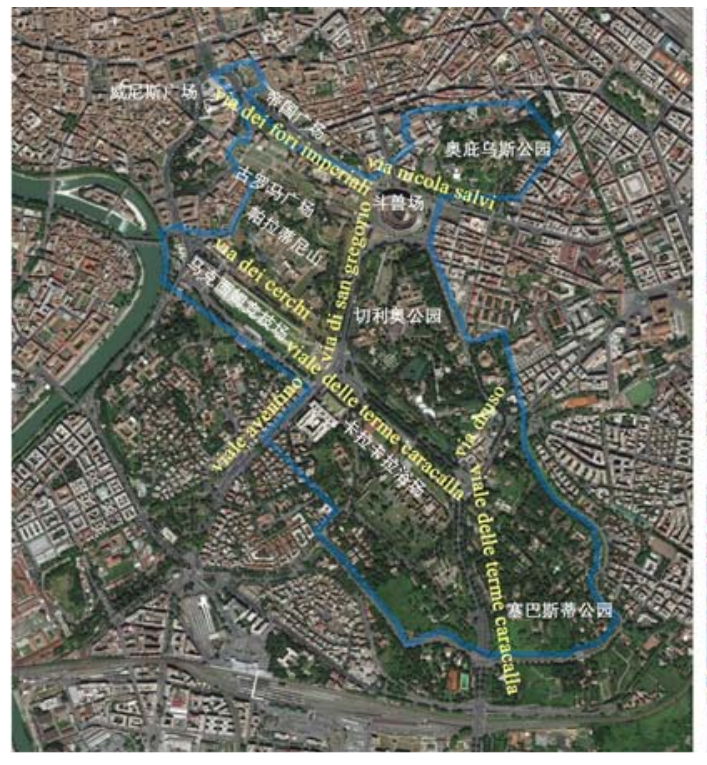

图例 城市街区

考古遗址中心 $\square$ 开放空间

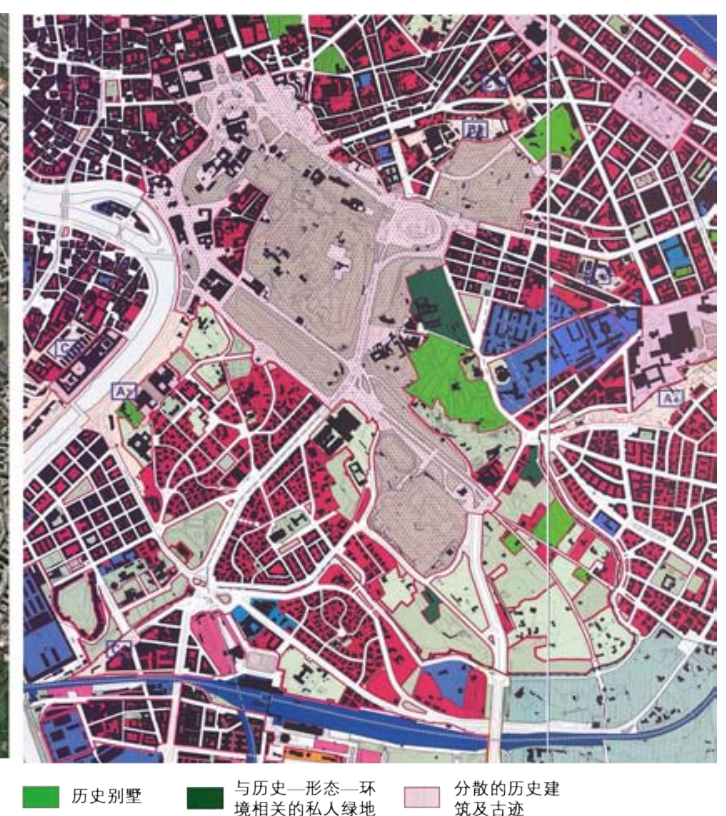

注: 左图蓝色线条为 1887 年划定的古迹区范围, 黄色字体表示贯穿古迹区的主要道路。

图 17 卫星图中的古迹区及其对应的用地性质

资料来源 : 左图源自谷歌地图, 右图源自罗马当前城市总体规划图 http://www.urbanistica.comune.roma.it/prg.html

(1) 2014 年, 罗马古迹区核心区参观人数超过名列第二的考古遗址庞贝 2621803 人次一倍有余。旅游对遗址的影响有利也有弊, 本文不作深入探讨。 
要未雨绸缪, 19 世纪末期的罗马古迹区正是这一类型的代表。 通常而言, 中心城区已被城市建设叠压的考古遗址不太可能 进行主动性挖掘, 整体揭露并保护展示的难度大, 偏远地区 的考古遗址所面临的城市建设压力相对较小, 恰恰是位于城 乡交界处的考古遗址最为脆弱。有这样区位特点的考古遗址 应当作为快速城市化过程中的重点监测对象，尽早划定保护 范围并对土地性质进行调整。

（3）大型考古遗址由于面域广、内部情况复杂、维护成 本高, 所对应管理模式并不一定是均质的。全域统筹、分而 治之的操作性强于无差别的管理与单一的运作模式。具体而 言, 各个区块的考古科研强度、开放程度、运营模式在不违 背保护原则的基础上可以有灵活调整的空间。同时引人社会 力量参与遗址的保护, 可以在分担政府维护成本的同时增加 利用上的多样性。

综上所述，遗址保护是一个长期的过程。规划只是遗址 保护的第一步，但对于未来发展的预见性有限。规划执行过 程中, 政治时局、文化氛围都是不确定因素, 对考古遗址的 影响并不完全可控。遗址的保护与利用，在社会的不同发展 阶段会有不同侧重点。对于这样的变动, 也不必持过于保守、
悲观的态度, 毕竟遗址保护的最终目的是服务于社会, 不可 能脱离社会发展而独立存在。寻找保护与发展的平衡, 做出 适当的动态性调整，才是文化遗产得以延续的途径。 UPI

\section{参考文献}

[1] 中国城市统计年鉴 [EB/OL]. [2018-01-22]. http://tongji.cnki.net/kns55/ Navi/HomePage.aspx?id=N2010042092\&name=YZGCA\&\#\#.

[2]单雾翔. 中国大型古代城市遗址的整体保护 [J]. 东南文化, 2009(2): 7-8.

[3] BENEVOLO L. Roma: studio per la sistemazione dell'area archeologica centrale[M]. Roma: De Luca, 1985: 14

[4] INSOLERA I. Archeologia e città, storia moderna dei Fori di Roma[M]. Roma; Bari: Laterza, 1999: XVIII.

[5] LUGLI P M. Urbanistica di Roma: trenta planimetrie per trenta secoli di storia[M]. Roma, Bardi, 1998: 124, 129.

[6] 穆方顺. 罗马交通为何挤而不堵 [J]. 科学咨询, 2005(17): 62

[7] Osservatorio Nazionale. Cultura e turismo: impresa e lavoro[R]. Rome: SL\&A, 2015: 10.

[8] LA REGINA A. Roma, continuità dell' antico: i Fori Imperiali nel progetto della città[M]. Milano: Electa, 1981: 53

[9] PANELLA R. Roma città e foro: questioni di progettazione del centro archeologico monumentale della capitale[M]. Roma: Officina, 1989: 32

[10] MENEGHINI R. I Fori Imperiali: gli scavi del comune di Roma (1991-2007) [M]. Roma : Viviani, 2007: 85

(本文编辑：王枫）

\section{(上接 85 页)}

映的和正在反映的物质并没有挡住他。……室内陈设仅仅是 装饰, 完全由孤立的居住空间决定, 它的那些室内陈设本身 的使用价值被剥离掉了, 因此, 室内装饰与那些室内陈设本 身的目的是不能相提并论的。……在商品世界里, 商品和商 品的社会本质淹没了商品自身。通过商品与它的使用价值相 分离, 那个商品的外部特征被社会地和经济地产生出。不过, 居室内部陈设的价值与使用价值联系在一起，保持不疏离的 状态。……舶来的东西把自己从疏离的东西转变成表达; 本 不会讲话的东西以 “符号” 说出了话。让室内设施有秩序, 我们称它为 “安排”。那些自古就有的幻象在室内出现了: 花 象征着生生不息, 东方象征着我们渴望的家园, 大海象征永 恒。历史的任何一个时刻都在责怪事物的外观。”

但是, 室内装饰也罢, 城市布置也罢, 不能千篇一律, 要有个性。在谈到理想的“个性” 时, 本雅明摘录了贝尼 （Adolf Behne）的这样一段话：“繁荣茂盛, 蜿蜒曲折, 错综 复杂, 我们朝着这个方向把所有的东西聚集在一起。然而, 读者的第一瞥也许看不到的是, 聚中有分, 分让我们重新成 为骑士。地上的地逃形成一个对角, 椅子可能形成一个对 角。不排除这种安排有偶然性, 可是, 当我们在所有阶级和 所有社会层次的住房里都照此办理, 布置室内家具, 形成对
角, 我们当然是在刻意安排, 而非巧合。……首先, 刻意安 排一个角度, 从而突显了一种个性, 这种个性很大程度上是 通过语言表达出来的。通过它摆放的角度, 物体让自己摆脱 了那个整体, 如同摆出角度的地毯。……对此的进一步解释 是, 下意识地保持了对立和防御的姿态。为了保护自己的地 盘, 我让自己呈现出一种角度, 这样, 我可以自由地看到两边。 恰恰是基于这样的理由, 建造堡垒的凸出部分, 以形成角度。 ……在这个意义上讲, 形成一个对角的地毯是不是重现了堡 垒中的那些凸出部分? 就像一个骑士, 他预计到他要受到的 攻击, 从而摆好一个姿势, 保证左右都不会受到攻击, 这样, 爱好和平的公民在若干世纪之后, 同样按照被墙和护城河环 绕着城堡的那种方式, 布置他自己的艺术品, 让他的艺术品 鹤立鸡群。其实, 他真的是一个俗人, 一个好斗的俗人。在 解释这个观点时, 作者半认真半开玩笑地讲, “一个能够拥 有别墅的人想要凸显自己的身份。还有比借助封建遗存和骑 士的形式更容易的方式吗? 卢卡奇 (György Lukács) 从历史 哲学的角度谈到了更一般的方式, 中产阶级的老对立面, 封 建制度, 还没有完全消失, 中产阶级的新对立面, 无产阶级, 已经登场, 这就是中产阶级的特点。中产阶级绝不会完全与 封建制度一刀两断。” $\boldsymbol{~ U P ~}$ 